\title{
Dihydroartemisinin transiently activates the JNK/SAPK signaling pathway in endothelial cells
}

\author{
FENGYUN DONG ${ }^{1 *}$, JU HAN ${ }^{2 *}$, GUOXIAN JING $^{2}$, XIAOCUI CHEN ${ }^{1}$, SUHUA YAN $^{3}$,

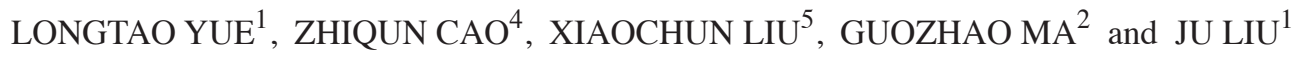 \\ ${ }^{1}$ Medical Research Center; ${ }^{2}$ Department of Neurology; ${ }^{3}$ Department of Cardiology, Shandong Provincial \\ Qianfoshan Hospital, Shandong University; ${ }^{4}$ Department of Medicine, Hospital of Shandong Traditional Chinese Medicine, \\ Jinan, Shandong 250014, P.R. China; ${ }^{5}$ Department of Investigational Cancer Therapeutics, \\ The University of Texas MD Anderson Cancer Center, Houston, TX 77030, USA
}

Received May 29, 2015; Accepted September 22, 2016

DOI: $10.3892 / \mathrm{ol} .2016 .5223$

\begin{abstract}
Artemisinin and its derivatives are well-known anti-malaria drugs and in the early stages of research for cancer treatment. Dihydroartemisinin (DHA), a more water-soluble derivative of artemisinin, has demonstrated strong anti-angiogenic activity. The purpose of the present study was to investigate the underlying molecular mechanisms of the effect of DHA on angiogenesis. Human umbilical vein endothelial cells (HUVECs) treated with DHA were examined for apoptosis and activation of the c-Jun N-terminal kinase (JNK) signaling pathway, one of the major mitogen-activated protein kinase cascades. It was observed that $20 \mu \mathrm{M}$ DHA induces transient activation of JNK in HUVECs. DHA also elevates the expression of cyclooxygenase- 2 and matrix metalloproteinase-13, which is abolished by treatment with the JNK inhibitor SP600125. Although DHA persistently increases inhibitor of $\kappa \mathrm{B}-\alpha$ protein and thus inhibits nuclear factor- $\kappa \mathrm{B}$ signaling, it does not affect apoptosis or caspase 3/9 activities in HUVECs. The present study provides key information for understanding the effects of DHA on endothelial cells, which is required for investigating its potential for clinic application as a chemotherapeutic agent.
\end{abstract}

Correspondence to: Professor Ju Liu, Medical Research Center, Shandong Provincial Qianfoshan Hospital, Shandong University, 16766 Jingshi Road, Jinan, Shandong 250014, P.R. China

E-mail: ju.liu@sdu.edu.cn

Dr Guozhao Ma, Department of Neurology, Shandong Provincial Qianfoshan Hospital, Shandong University, 16766 Jingshi Road, Jinan, Shandong 250014, P.R. China

E-mail:maguozhao@163.com

*Contributed equally

Key words: dihydroartemisinin, c-Jun N-terminal kinase signaling, angiogenesis, endothelial cell, apoptosis

\section{Introduction}

Angiogenesis refers to the formation of new capillaries from pre-existing blood vessels (1). Solid tumor growth depends on angiogenesis to supply nutrients and dispose of catabolic products (2). Without new blood vessels, tumor cells cannot sustain proliferation and thus are likely to remain dormant (3). Anti-angiogenesis has become a significant adjuvant treatment strategy in cancer chemotherapy (3). Over the previous decade, numerous anti-angiogenic agents have been developed, and some of these have been approved by the FDA. These agents include bevacizumab, sorafenib and sunitinib $(4,5)$. However, not all cancer patients benefit from existing anti-angiogenic therapies (4-6). Novel anti-angiogenic strategies are required to improve the prognosis of such patients.

Tumor angiogenesis is a tightly controlled process, which is initiated by the secretion of growth factors, including vascular endothelial growth factor (VEGF), from tumor cells (7). These growth factors bind to their receptors on endothelial cells and activate intracellular signal transduction pathways to modify endothelial cell proliferation, migration, apoptosis and differentiation (7). The mitogen-activated protein kinase (MAPK) signaling pathway is a signaling cascade that mediates diverse extracellular stimuli and regulates key cellular functions (8). In mammals, MAPKs have three major subfamilies: Extracellular signal-regulated kinase (ERK1/2 or p44/42 MAPK), p38 MAPK and c-Jun N-terminal kinase (JNK)/stress-activated protein kinase (SAPK) (9). JNK has three isoforms (JNK1, 2 and 3). JNK1 and JNK2 are expressed in the majority of cell types, including endothelial cells, while JNK3 is mainly expressed in neuronal tissues (10-13). The JNK signaling pathway is activated primarily by cytokines or exposure to environmental stresses $(10,14)$. These extracellular stimuli trigger the activation of MAP kinase kinase kinases, which subsequently phosphorylate the mitogen-activated protein kinase kinase isoforms mitogen-activated protein kinase kinase (MKK)4 and MKK7. MKKs are dual-specificity protein kinases that phosphorylate JNK at Thr183 and Tyr185 (10,14). JNK specifically phosphorylates the transcription factor c-Jun on its N-terminal transactivation domain at two serine residues, Ser63 and Ser73 (15). JNK and c-Jun 
activate transcription factors, including activator protein 1, activating transcription factor 2, Elk-1, p53 and c-Myc (16), which consequently regulate downstream genes involved in apoptosis, proliferation and differentiation $(17,18)$. In addition, the JNK cascade is modulated by Notch, nuclear factor (NF)- $\kappa \mathrm{B}$ and other signaling pathways $(16,19)$.

Artemisinin is a lactonic sesquiterpenoid compound originally isolated from Artemisia annua $L$ and has been used to treat malaria since the 1970 s (20). An artemisinin derivative, dihydroartemisinin (DHA), is more water-soluble and currently considered the most effective drug in treating cerebral malaria $(21,22)$. DHA has also demonstrated strong anti-tumor activity (23). Recently, DHA emerged as a promising agent with potent anti-angiogenic properties (24). DHA represses the expression of VEGF in several cancer cell lines $(23,25)$. In cultured endothelial cells, DHA inhibits proliferation, migration and tube formation (26-28). In a mouse model of retinal neovascularization, intravitreal injection of DHA reduced angiogenesis (24). As a widely used anti-malarial drug, DHA has been proven to be safe with minimal side effects and may be used clinically as a component of cancer chemotherapy (29). However, mechanistic studies of its anti-angiogenic effects at low concentrations are limited. Previously, the present authors reported that $20 \mu \mathrm{M}$ of DHA (estimated C-max of the treatment of $12 \mathrm{mg} / \mathrm{kg}$ body weight recommended by the World Health Organisation for antimalarial therapy) inhibits endothelial cell proliferation by suppression of phosphorylation and protein expression of ERK1/2 (30), whereas it does not affect p38 MAPK in endothelial cells (31). The role of the JNK signaling pathway in the response of endothelial cells to DHA remains unclear.

In the present study, the effects of DHA on JNK signaling were investigated in human umbilical vein endothelial cells (HUVECs). At a concentration of $20 \mu \mathrm{M}$, DHA transiently activated JNK and increased the expression of JNK signaling pathway downstream genes. An identical concentration of DHA inhibited the NF- $\mathrm{BB}$ signaling pathway, but did not affect endothelial cell apoptosis. The results of the present study may improve our understanding of the molecular mechanisms of the anti-angiogenic activities of DHA.

\section{Materials and methods}

Cell culture. HUVECs were purchased from Lonza (Basel, Switzerland) and cultured in basal endothelial cell medium (EBM2) supplemented with EGM-2-MV bullet kit (Lonza) and antibiotics (100 IU/ml penicillin and $100 \mu \mathrm{g} / \mathrm{ml}$ streptomycin). The cells were placed in humidified air at $37^{\circ} \mathrm{C}$ with 5\% $\mathrm{CO}_{2}$. DHA (D7439; Sigma-Aldrich; EMD Millipore, Billerica, MA, USA), pyrrolidine dithiocarbamate (PDTC; P8765; Sigma-Aldrich; EMD Millipore) and SP600125 (8177; Cell Signaling Technology, Inc., Danvers, MA, USA) were dissolved in dimethyl sulfoxide. In this study, $20 \mu \mathrm{M}$ DHA, $100 \mu \mathrm{M}$ PDTC, $10 \mu \mathrm{M}$ JNK inhibitor SP600125 and $10 \mu \mathrm{M}$ anisomycin, were used to treat the cells.

Western blotting. Cells were washed with cold PBS and lysed in radioimmunoprecipitation assay buffer $(20 \mathrm{mM}$ Tris pH 7.5, $150 \mathrm{mM} \mathrm{NaCl}, 50 \mathrm{mM} \mathrm{NaF}, 1 \% \mathrm{NP} 40,0.1 \%$ DOC, $0.1 \%$ SDS, $1 \mathrm{mM}$ EDTA, $1 \mathrm{mM}$ phenylmethylsulfonyl fluoride and $1 \mu \mathrm{g} / \mathrm{ml}$ leupeptin). Protein concentrations of the cell lysates were determined using the bicinchoninic acid assay (Bio-Rad Laboratories, Inc., Hercules, CA, USA). Equal amounts of the protein $(25 \mu \mathrm{g})$ from each sample were separated by SDS-PAGE (7.5\% polyacrylamide gel) and transferred on to a PVDF membrane, which was blocked with $2.5 \%$ non-fat milk and incubated overnight with primary antibody in PBS-T at $4^{\circ} \mathrm{C}$. Immunoreactivity was detected with horseradish peroxidase-conjugated goat anti-rabbit immunoglobulin G secondary antibody (1:2,000; 7074; Cell Signaling Technology, Inc.) for $30 \mathrm{~min}$ at room temperature, and visualized with enhanced chemiluminescence (Pierce ECL; Thermo Fisher Scientific, Inc., Waltham, MA, USA). The primary antibodies included rabbit anti-phospho-SAPK/ JNK (Thr183/Tyr185) $(1: 1,000 ; 81 E 11)$, rabbit anti-SAPK/ JNK $(1: 2,000 ; 9252)$, mouse anti-inhibitor of kappa B (IкB)- $\alpha$ (1:1,000; L35A5; Cell Signaling Technology, Inc.) and anti- $\beta$-actin antibodies (1:5,000; A2228; Sigma-Aldrich; Merck Millipore, Darmstadt, Germany). The densitometry analyses were performed using ImageJ software $(\mathrm{NIH}$, Bethesda, MD).

Reverse transcription-quantitative polymerase chain reaction. Total RNA from the cells was extracted using the RNeasy Mini kit (Qiagen GmbH, Hilden, Germany) and cDNA was synthesized using High Capacity RNA-to-cDNA Master mix (Applied Biosystems; Thermo Fisher Scientific, Inc.). RT-qPCR was performed using SYBR Green Master Mix (Thermo Fisher Scientific, Inc.) and a ViiA7 Real-Time PCR system (Thermo Fisher Scientific, Inc.) with the following cycling conditions: $50^{\circ} \mathrm{C}$ for $2 \mathrm{~min}$ and $95^{\circ} \mathrm{C}$ for $2 \mathrm{~min}$, followed by 40 cycles of $95^{\circ} \mathrm{C}$ for $15 \mathrm{sec}$ and $58^{\circ} \mathrm{C}$ for $1 \mathrm{~min}$.. All PCR reactions were repeated in triplicate. Relative expression was calculated using GAPDH as an internal control and calculated following the $\Delta \Delta \mathrm{Cq}$ method (32). The primer sequences are summarized in Table I.

Caspase activity assay. The bioactivity of caspase-3 and -9 was measured with a Fluorometric Assay kit (Abcam, Cambridge, UK) according to the manufacturer's protocol. Briefly, the cells were collected after $20 \mu \mathrm{M}$ DHA treatment for $24 \mathrm{~h}$ and incubated with the caspase-3 substrate DEVD-AFC or the caspase-9 substrate LEHD-AFC. The fluorescence of the cleaved substrates was determined at an excitation wavelength of $400 \mathrm{~nm}$ and an emission wavelength of $505 \mathrm{~nm}$ using a fluorescence plate reader (Molecular Devices, LLC, Sunnyvale, CA, USA).

Annexin V-fluorescein isothiocyanate (FITC)/propidium iodide (PI) analyses. The apoptosis of HUVECs treated with DHA and/or the inhibitors was detected by annexin V-FITC and propidium iodide (PI) staining according to the manufacturer's protocol of the Apoptosis Detection kit (Neobiosciences, Shenzhen, China). Briefly, the cells were collected by trypsinization and resuspended in binding buffer containing annexin V-FITC (0.25\%) and PI ( $1 \mu \mathrm{g} / \mathrm{ml})$. Detection of the cells with positive staining was performed using a FACSAria II flow cytometer (BD Biosciences, San Jose, CA, USA). The data were analyzed with the FACS Diva acquisition and analysis software version 11.5 (BD Biosciences). 
Table I. Reverse-transcription polymerase chain reaction primer sequences.

\begin{tabular}{llr}
\hline Gene & \multicolumn{1}{c}{ Sequence } & Size, bp \\
\hline $\begin{array}{l}\text { Cyclooxygenase-2 } \\
\text { Sense }\end{array}$ & GAATCATTCACCAGGCAAATTG ${ }^{\circ} \mathrm{C}$ \\
Anti-sense & TCTGTACTGCGGGTGGAACA & 67 \\
Matrix metalloproteinase 13 & & 58.5 \\
Sense & TCCCAGGAATTGGTGATAAAGTAGA & 123 \\
Anti-sense & CTGGCATGACGCGAACAATA & 240 \\
GAPDH & TGATGACATCAAGAAGGTGGTGAAG & 63.5 \\
Sense & TCCTTGGAGGCCATGTGGGCCAT & \\
Anti-sense & & \\
\hline
\end{tabular}

All sequences are in the $5^{\prime}$ to $3^{\prime}$ orientation. bp, base pair; Tm, melting temperature.

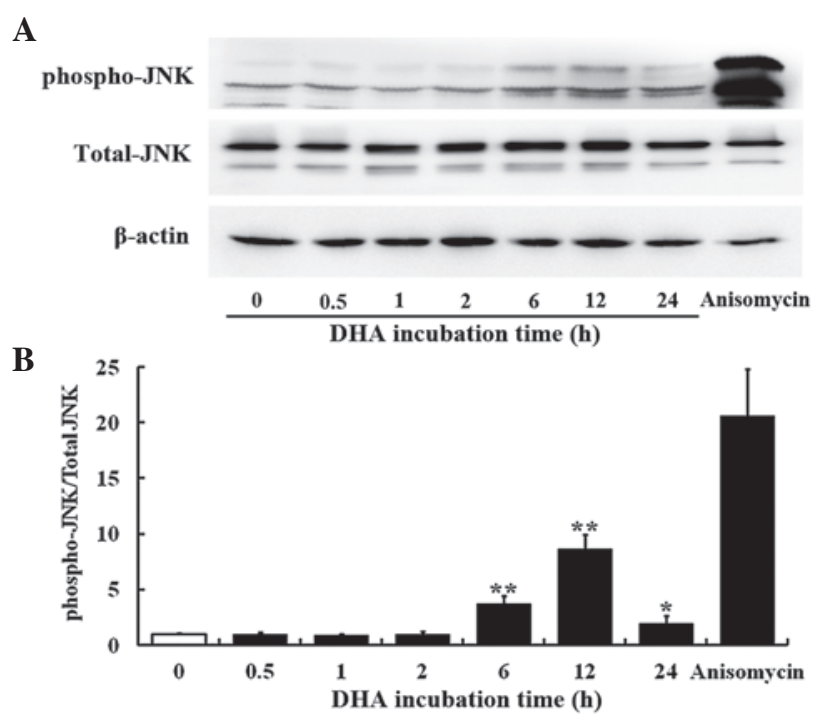

Figure 1. DHA transiently activates JNK in endothelial cells. (A) Representative immunoblots of phospho-JNK, total JNK and $\beta$-actin from protein samples of human umbilical vein endothelial cells treated with DHA at various time points. (B) Densitometry analysis of the blots of phospho-JNK and total JNK. $\mathrm{n}=3 ;{ }^{*} \mathrm{P}<0.05 ;{ }^{* *} \mathrm{P}<0.01$, compared with the control. DHA, dihydroartemisinin.

Statistical analysis. Data were expressed as the mean \pm standard error. Comparison of means was achieved by the unpaired, two-tailed Student's t-test. Statistical analyses were performed using SPSS version 11.5 (SPSS, Inc., Chicago, IL, USA). P<0.05 was considered to indicate a statistically significant difference.

\section{Results}

DHA transiently activates JNK in endothelial cells. The JNK signaling pathway mediates cellular responses to extracellular stimuli and is involved in angiogenesis (14). The present study investigated the effects of $20 \mu \mathrm{M}$ DHA on phosphorylation of JNK in HUVECs by western blotting. The protein levels of the total JNK remained unaffected at all time points; however, the phospho-JNK level was elevated at 6, 12 and $24 \mathrm{~h}$ incubation with DHA (Fig. 1A). Densitometry analysis revealed that the ratio of phospho-JNK/total-JNK was significantly increased
A

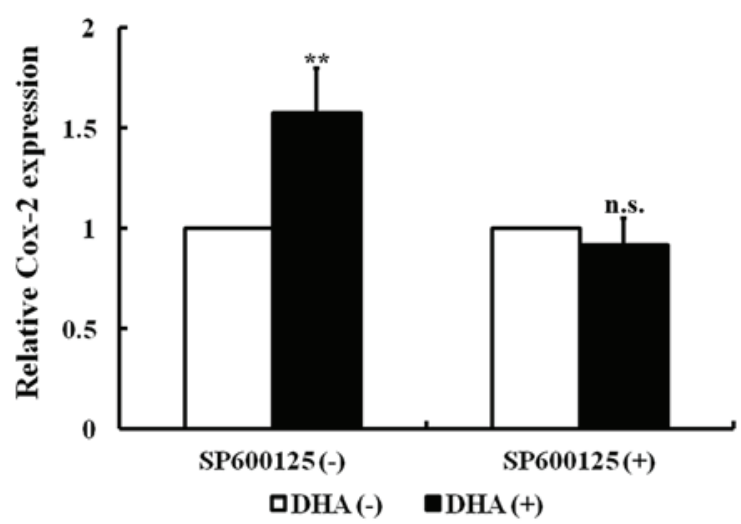

B

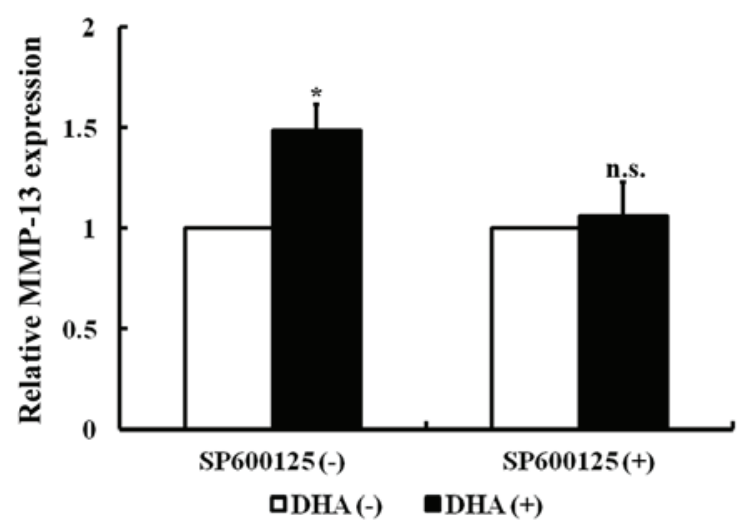

Figure 2. DHA induces expression of JNK downstream genes. (A) RT-PCR analyses of relative Cox-2 mRNA expression in HUVECs treated with DHA and/or SP600125. (B) RT-PCR analyses of relative MMP-13 mRNA expression in HUVECs treated with DHA and/or SP600125. $\mathrm{n}=4 ;{ }^{*} \mathrm{P}<0.05 ;{ }^{* *} \mathrm{P}<0.01$. DHA, dihydroartemisinin; RT-PCR, reverse transcription-polymerase chain reaction; Cox-2, cyclooxygenase-2; HUVECs, human umbilical vein endothelial cells; MMP-13, matrix metalloproteinase-13; n.s., non-significant.

at $6 \mathrm{~h}(\mathrm{P}=0.001)$, reached a peak at $12 \mathrm{~h}(\mathrm{P}=0.003)$ and subsequently decreased from the peak at $24 \mathrm{~h}(\mathrm{P}=0.020)$ following DHA treatment (Fig. 1B), suggesting that DHA transiently activates the JNK signaling pathway. Anisomycin is a phenylpyrolidine derivative that strongly activates JNK (33); thus, it was used as a positive control in the present study. Anisomycin markedly increased the level of phospho-JNK in HUVECs (Fig. 1A and B). 


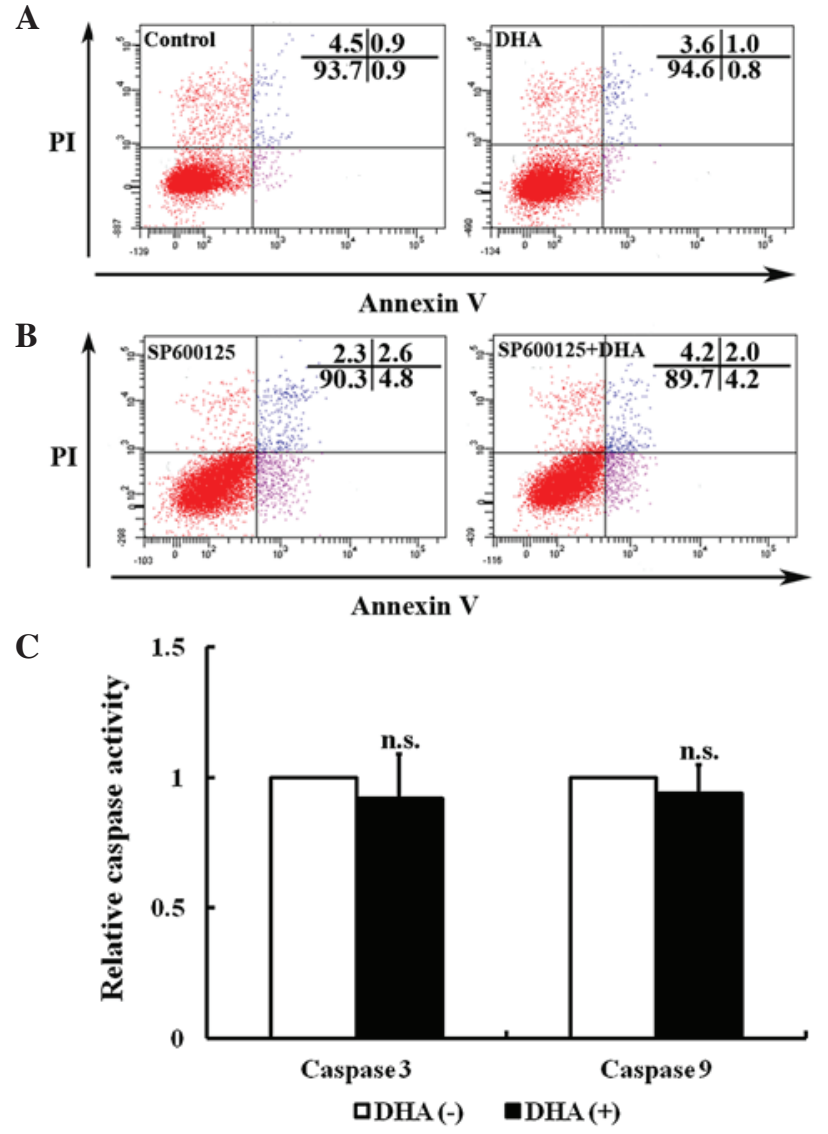

Figure 3. Effects of DHA on endothelial cell apoptosis. Representative images of flow cytometry detection with Annexin V/PI double-staining for (A) HUVECs treated with 0 and $20 \mu \mathrm{M}$ DHA for $24 \mathrm{~h}$ and (B) HUVECs treated with 0 and $20 \mu \mathrm{M}$ DHA for $24 \mathrm{~h}$ following pretreatment with $10 \mu \mathrm{M}$ SP600125. (C) Caspase activity assay for HUVECs treated with 0 and $20 \mu \mathrm{M}$ DHA for 24 h. n=12. n.s., non-significant; DHA, dihydroartemisinin; PI, propidium iodide; HUVECs, human umbilical vein endothelial cells.

DHAinduces the expression of the downstream genes of the JNK signaling pathway in endothelial cells. In endothelial cells, the JNK signaling pathway specifically mediates the expression of cyclooxygenase-2 (Cox-2) and matrix metalloproteinase-13 (MMP-13) in response to a variety of cytokines $(34,35)$. As revealed by RT-PCR, Cox-2 and MMP-13 transcription was significantly increased in HUVECs following treatment with $20 \mu \mathrm{M}$ DHA for $24 \mathrm{~h}(\mathrm{P}=0.010$ and $\mathrm{P}=0.020$, respectively; Fig. 2A and B). SP600125 is an anthrapyrazolone inhibitor of JNK (36). With pretreatment of $10 \mu \mathrm{M}$ SP600125 for $1 \mathrm{~h}$, DHA failed to increase the mRNA levels of Cox-2 and MMP-13 ( $\mathrm{P}=0.08$ and $\mathrm{P}=0.11$, respectively) (Fig. $2 \mathrm{~A}$ and $\mathrm{B}$ ). Thus, DHA induces expression of Cox-2 and MMP-13 via transient activation of the JNK signaling pathway.

DHA does not induce JNK-mediated apoptosis in endothelial cells. Apoptosis, a type of programmed cell death, is a critical process that is altered during angiogenesis (37). JNK signaling activates intrinsic apoptotic signaling pathways by modulating the activities of pro- and anti-apoptotic proteins in mitochondria through phosphorylation (16). The present study investigated the effects of low dose DHA $(20 \mu \mathrm{M})$ on endothelial cell apoptosis by flow cytometry. As shown by Fig. 3A, DHA treatment does not alter the percentage of viable cells

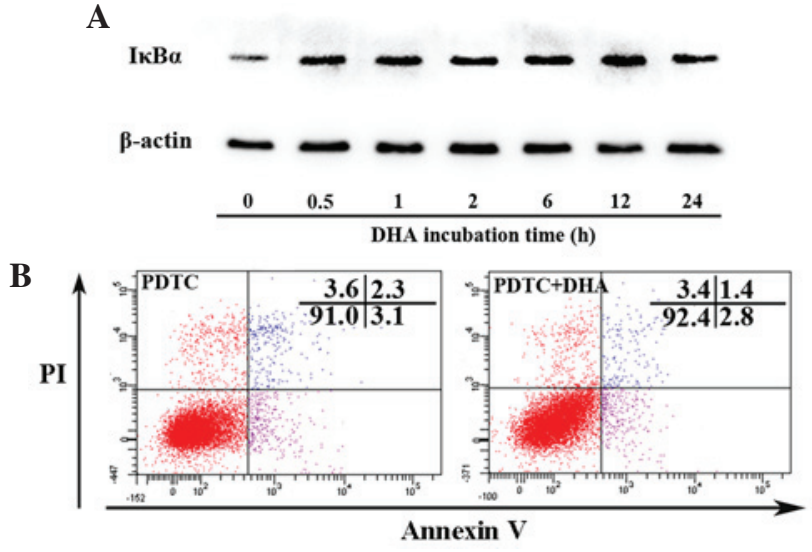

Figure 4. DHA inhibits the nuclear factor- $\kappa \mathrm{B}$ signaling pathway in endothelial cells. (A) Representative immunoblots of I $\mathrm{B}$ - $\alpha$ and $\beta$-actin from protein samples of HUVECs treated with DHA at various time points. (B) Representative images of flow cytometry detection with Annexin V/PI double-staining for HUVECs treated with 0 and $20 \mu \mathrm{M}$ DHA for $24 \mathrm{~h}$ following pretreatment with $100 \mu \mathrm{M}$ PDTC. DHA, dihydroartemisinin; HUVECs, human umbilical vein endothelial cells; PI, propidium iodide; PDTC, pyrrolidine dithiocarbamate; IкB- $\alpha$, inhibitor of $\kappa$ B-. $\alpha$.

(93.4 \pm 2.2 vs. $93.8 \pm 3.1 ; \mathrm{P}=0.33$ ) (Fig. $3 \mathrm{~A}$ ). Following pretreatment with $10 \mu \mathrm{M}$ JNK inhibitor SP600125, the percentage of viable cells remained unaffected by DHA treatment $(91.3 \pm 2.7$ vs. 90.8 $\pm 1.6 ; \mathrm{P}=0.09$ ) (Fig. 3B). JNK may increase caspase 3 and 9 activities to facilitate apoptosis (38). However, treatment with $20 \mu \mathrm{m}$ DHA does not alter the activities of caspase 3 and 9 in HUVECs ( $\mathrm{P}=0.21$ and $\mathrm{P}=0.18$, respectively) (Fig. 3C). Taken together, the results of the present study appear to indicate that low dose DHA does not affect apoptosis in endothelial cells.

DHA persistently inhibits the $N F-\kappa B$ signaling pathway in endothelial cells. Nuclear factor- $\mathrm{\kappa B}$ (NF- $\mathrm{\kappa B})$ signaling regulates expression of a large number of genes that are critical for the regulation of apoptosis, which is mediated in part by its ability to downregulate JNK activation (39). Activation of $\mathrm{NF}-\kappa \mathrm{B}$ requires the degradation of I $\mathrm{B}-\alpha$, which binds with the p65-p50 heterodimer and blocks the nuclear translocation of the NF- $\kappa B$ subunits (39). The present study assessed whether DHA affects IкB- $\alpha$ by western blotting. As shown in Fig. 4A, the protein level of IкB- $\alpha$ began to increase at $0.5 \mathrm{~h}$ and peaked at $12 \mathrm{~h}$ following treatment with $20 \mu \mathrm{M}$ DHA. PDTC is a potent inhibitor of the NF- $\kappa \mathrm{B}$ signaling pathway that inhibits I $\mathrm{KB}-\alpha$ degradation, precludes the dissociation of $\mathrm{NF}-\kappa \mathrm{B}$ from I $\kappa \mathrm{B}-\alpha$ and thus prevents translocation of NF- $\kappa \mathrm{B}$ to the nucleus (40). Following pretreatment with $100 \mu \mathrm{M}$ PDTC for $1 \mathrm{~h}$, DHA showed no effect on apoptosis as determined by the percentage of viable cells $(91.1 \pm 1.9$ vs. $91.6 \pm 2.5$; $\mathrm{P}=0.17$ ) (Fig. 4B). Though DHA inhibits the NF- $\mathrm{kB}$ signaling pathway by upregulation of IкB- $\alpha$, it does not affect apoptosis via NF-kB dependent or independent signaling pathways.

\section{Discussion}

The artemisinin family of drugs demonstrates potent inhibitory effects on angiogenesis; however, the underlying molecular mechanisms remain unclear. In the present study, the role of DHA, a water-soluble metabolite of artemisinin derivatives, 
on the JNK signaling in endothelial cells was examined. It was observed that DHA transiently activates JNK and upregulates the expression of JNK signaling pathway downstream genes, which can be abolished by JNK inhibitor SP600125. In addition, DHA does not affect apoptosis or caspase activity despite persistently inhibiting the NF- $\kappa \mathrm{B}$ signaling pathway.

Angiogenesis is a complex process regulated by multiple signaling pathways (37). Many of the angiogenic pathways overlap, resulting in redundancy or contradiction within the angiogenic system (37). MAPK cascades are involved in mediating the effects of angiogenic and anti-angiogenic factors $(41,42)$. It has previously been reported that DHA inhibits endothelial cell proliferation by suppression of ERK signaling (30), while it does not alter p38 MAPK (31). In the present study, it was observed that DHA activates transient but not prolonged JNK activation in HUVECs. The expression of Cox-2 and MMP13, the downstream genes of JNK activation in endothelial cells, were also upregulated by DHA. Thus, DHA acted distinctly on the three major MAPK signaling pathways in endothelial cells. The differential regulation of MAPK cascades was also observed in other stress responses (43). JNK signaling is a positive and negative regulator of angiogenesis (44). Inhibition of JNK reduced endothelial cell proliferation, migration and proteolysis of the capillary basement membrane (45). By contrast, the JNK signaling pathway mediates the anti-angiogenesis effects of various agents by increasing endothelial cell apoptosis (46). Delineation of the effects of DHA on specific signaling pathways may assist with the use of this agent through combination therapy.

Activation of JNK promotes apoptosis in a context-specific fashion (13). Studies using deficient or constitutively active components of the JNK signaling pathway indicate that activation of JNK increases apoptosis $(47,48)$. However, the pro-apoptotic role of the JNK signaling pathway depends on the experimental settings. Under certain circumstances, JNK signaling also serves an anti-apoptotic role (49) or has no effects on apoptosis (50). Though DHA activates transient JNK activation, it was observed that DHA does not inhibit endothelial cell apoptosis. In addition, DHA has no effect on the activities of caspase 3 and 9, which is activated by the JNK signaling pathway and mediates the JNK-dependent mitochondrial apoptotic signaling pathway (38). The effects of JNK activation on apoptosis were distinguished by the varying activation patterns, transient vs. prolonged/persistent, respectively. Previous studies demonstrated that prolonged activation of JNK promotes tumor necrosis factor (TNF)- $\alpha$-induced apoptosis, but conversion of JNK activation from prolonged to transient suppresses TNF- $\alpha$-induced apoptosis (51). The effects of transient JNK activation alone on apoptosis remain controversial, while various stimuli induced transient JNK activation without causing apoptotic cell death (52).

The NF- $\mathrm{B}$ signaling pathway is a negative regulator of apoptosis, and its anti-apoptotic function is mediated in part through downregulation of JNK activation (52). DHA induced a sustained increase of $\mathrm{I} \kappa \mathrm{B}$, indicating its inhibitory role on $\mathrm{NF}-\kappa \mathrm{B}$ signaling. Thus, the transient action of JNK may be caused by the inhibitory effects of DHA on NF- $\kappa \mathrm{B}$ signaling. However, DHA does not affect apoptosis in the absence or presence of $\mathrm{NF}-\kappa \mathrm{B}$ inhibitor. In fibroblasts, suppression of $N F-\kappa B$ induces prolonged (rather than transient) JNK activation, leading to increased apoptosis (53). However, the crosstalk between NF- $\mathrm{BB}$ and JNK is complicated (52). In TNF- $\alpha$-treated NF- $\kappa$ B-deficient cells, persistent JNK activation promotes cell survival (54). In the present study, DHA showed no significant effect on apoptosis although it inhibited $\mathrm{NF}-\kappa \mathrm{B}$ and transiently activated JNK signaling. Thus, NF- $\kappa \mathrm{B}-$ regulated activation of JNK regulates apoptosis based on death stimulus and cell types.

In summary, the present study observed that low concentration of DHA induces transient activation of JNK signaling without triggering apoptosis in endothelial cells. The results of the present study provide important information concerning the molecular mechanisms that underlie the anti-angiogenic activities of DHA, which is essential for investigating its potential for clinical application.

\section{Acknowledgements}

The present study was supported by grants from the Science and Technology Development Plan of Jinan City (grant no. 201303026) and the Medical Science Development Plan of Shandong Province (grant no. 2013WS0137. The authors are grateful for the support from the Shandong Taishan Scholarship (awarded to Professor Ju Liu).

\section{References}

1. Carmeliet P: Angiogenesis in life, disease and medicine. Nature 438: 932-936, 2005.

2. Cao Y: Antiangiogenic cancer therapy: Why do mouse and human patients respond in a different way to the same drug? Int J Dev Biol 55: 557-562, 2011.

3. Ferrara N and Kerbel RS: Angiogenesis as a therapeutic target. Nature 438: 967-974, 2005.

4. Bergers $G$ and Hanahan D: Modes of resistance to anti-angiogenic therapy. Nat Rev Cancer 8: 592-603, 2008.

5. Ellis LM and Hicklin DJ: Pathways mediating resistance to vascular endothelial growth factor-targeted therapy. Clin Cancer Res 14: 6371-6375, 2008.

6. Chen HX and Cleck JN: Adverse effects of anticancer agents that target the VEGF pathway. Nat Rev Clin Oncol 6: 465-477, 2009.

7. Folkman J: Angiogenesis in cancer, vascular, rheumatoid and other disease. Nat Med 1: 27-31, 1995.

8. Hoefen RJ and Berk BC: The role of MAP kinases in endothelial activation. Vascul Pharmacol 38: 271-273, 2002.

9. Page C and Doubell AF: Mitogen-activated protein kinase (MAPK) in cardiac tissues. Mol Cell Biochem 157: 49-57, 1996.

10. Davis RJ: Signal transduction by the JNK group of MAP kinases. Cell 103: 239-252, 2000.

11. Chang L and Karin M: Mammalian MAP kinase signalling cascades. Nature 410: 37-40, 2001

12. Shaulian E and Karin M: AP-1 as a regulator of cell life and death. Nat Cell Biol 4: E131-E136, 2002.

13. Lin A: Activation of the JNK signaling pathway: Breaking the brake on apoptosis. Bioessays 25: 17-24, 2003.

14. Weston CR and Davis RJ: The JNK signal transduction pathway. Curr Opin Genet Dev 12: 14-21, 2002.

15. Hibi M, Lin A, Smeal T, Minden A and Karin M: Identification of an oncoprotein- and UV-responsive protein kinase that binds and potentiates the c-Jun activation domain. Genes Dev 7: 2135-2148, 1993.

16. Liu J and Lin A: Role of JNK activation in apoptosis: A double-edged sword. Cell Res 15: 36-42, 2005.

17. Zhang J, Guo L, Zhou X, Dong F, Li L, Cheng Z, Xu Y, Liang J, Xie Q and Liu J: Dihydroartemisinin induces endothelial cell anoikis through the activation of the JNK signaling pathway. Oncol Lett 12: 1896-1900, 2016.

18. Kang YJ, Jeon ES, Song HY, Woo JS, Jung JS, Kim YK and Kim JH: Role of c-Jun N-terminal kinase in the PDGF-induced proliferation and migration of human adipose tissue-derived mesenchymal stem cells. J Cell Biochem 95: 1135-1145, 2005. 
19. Cheng YL, Choi Y, Seow WL, Manzanero S, Sobey CG, Jo DG and Arumugam TV: Evidence that neuronal Notch-1 promotes JNK/c-Jun activation and cell death following ischemic stress. Brain Res 1586: 193-202, 2014.

20. Tu Y: The development of new antimalarial drugs: Qinghaosu and dihydro-qinghaosu. Chin Med J (Engl) 112: 976-977, 1999.

21. White NJ: Qinghaosu (artemisinin): The price of success Science 320: 330-334, 2008.

22. van Hensbroek MB, Onyiorah E, Jaffar S, Schneider G, Palmer A, Frenkel J, Enwere G, Forck S, Nusmeijer A, Bennett S, et al: A trial of artemether or quinine in children with cerebral malaria. N Engl J Med 335: 69-75, 1996.

23. Chen HH, Zhou HJ, Wang WQ and Wu GD: Antimalarial dihydroartemisinin also inhibits angiogenesis. Cancer Chemother Pharmacol 53: 423-432, 2004.

24. Dong F, Zhou X, Li C, Yan S, Deng X, Cao Z, Li L, Tang B, Allen TD and Liu J: Dihydroartemisinin targets VEGFR2 via the NF-kB pathway in endothelial cells to inhibit angiogenesis. Cancer Biol Ther 15: 1479-1488, 2014.

25. Zhou HJ, Wang WQ, Wu GD, Lee J and Li A: Artesunate inhibits angiogenesis and downregulates vascular endothelial growth factor expression in chronic myeloid leukemia K562 cells. Vascul Pharmacol 47: 131-138, 2007.

26. Chen HH, Zhou HJ and Fang X: Inhibition of human cancer cell line growth and human umbilical vein endothelial cell angiogenesis by artemisinin derivatives in vitro. Pharmacol Res 48 231-236, 2003.

27. Wu GD, Zhou HJ and Wu XH: Apoptosis of human umbilical vein endothelial cells induced by artesunate. Vascul Pharmacol 41: 205-212, 2004

28. D'Alessandro S, Basilico N, Corbett Y, Scaccabarozzi D, Omodeo-Salè F, Saresella M, Marventano I, Vaillant M, Olliaro P and Taramelli D: Hypoxia modulates the effect of dihydroartemisinin on endothelial cells. Biochem Pharmacol 82: 476-484, 2011

29. Ho WE, Peh HY, Chan TK and Wong WS: Artemisinins: Pharmacological actions beyond anti-malarial. Pharmacol Ther 142: 126-139, 2014.

30. Dong F, Tian H, Yan S, Li L, Dong X, Wang F, Li J, Li C, Cao Z, Liu X and Liu J: Dihydroartemisinin inhibits endothelial cell proliferation through the suppression of the ERK signaling pathway. Int J Mol Med 35: 1381-1387, 2015.

31. Guo L, Dong F, Hou Y, Cai W, Zhou X, Huang AL, Yang M, Allen TD and Liu J: Dihydroartemisinin inhibits vascular endothelial growth factor-induced endothelial cell migration by a p38 mitogen-activated protein kinase-independent pathway. Exp Ther Med 8: 1707-1712, 2014.

32. Pinent M, Hackl H, Burkard TR, Prokesch A, Papak C, Scheideler M, Hämmerle G, Zechner R, Trajanoski Z and Strauss JG: Differential transcriptional modulation of biological processes in adipocyte triglyceride lipase and hormone-sensitive lipase-deficient mice. Genomics 92: 26-32, 2008.

33. Cano E, Hazzalin CA and Mahadevan LC: Anisomycin-activated protein kinases p45 and p55 but not mitogen-activated protein kinases ERK-1 and -2 are implicated in the induction of c-fos and c-jun. Mol Cell Biol 14: 7352-7362, 1994.

34. Li Z, Meng D, Li G, Xu J, Tian K and Li Y: Celecoxib combined with diacerein effectively alleviates osteoarthritis in rats via regulating JNK and p38MAPK signaling pathways. Inflammation 38: 1563-1572, 2015

35. Kohlstedt K, Busse R and Fleming I: Signaling via the angiotensin-converting enzyme enhances the expression of cyclooxygenase-2 in endothelial cells. Hypertension 45: 126-132, 2005.

36. Bennett BL, Sasaki DT, Murray BW, O'Leary EC, Sakata ST, Xu W, Leisten JC, Motiwala A, Pierce S, Satoh Y, et al: SP600125, an anthrapyrazolone inhibitor of Jun N-terminal kinase. Proc Natl Acad Sci USA 98: 13681-13686, 2001.
37. Carmeliet P and Jain RK: Molecular mechanisms and clinical applications of angiogenesis. Nature 473: 298-307, 2011.

38. Cho SG and Choi EJ: Apoptotic signaling pathways: Caspases and stress-activated protein kinases. J Biochem Mol Biol 35: 24-27, 2002.

39. Bubici C, Papa S, Pham CG, Zazzeroni F and Franzoso G: The NF-kappaB-mediated control of ROS and JNK signaling. Histol Histopathol 21: 69-80, 2006.

40. Liu SF, Ye X and Malik AB: Pyrrolidine dithiocarbamate prevents I-kappaB degradation and reduces microvascular injury induced by lipopolysaccharide in multiple organs. Mol Pharmacol 55: 658-667, 1999.

41. Harris VK, Coticchia CM, Kagan BL, Ahmad S, Wellstein A and Riegel AT: Induction of the angiogenic modulator fibroblast growth factor-binding protein by epidermal growth factor is mediated through both MEK/ERK and p38 signal transduction pathways. J Biol Chem 275: 10802-10811, 2000.

42. Huynh-Do U, Vindis C, Liu H, Cerretti DP, McGrew JT, Enriquez M, Chen J and Daniel TO: Ephrin-B1 transduces signals to activate integrin-mediated migration, attachment and angiogenesis. J Cell Sci 115: 3073-3081, 2002.

43. Liu J and Kapron CM: Differential induction of MAP kinase signalling pathways by cadmium in primary cultures of mouse embryo limb bud cells. Reprod Toxicol 29: 286-291, 2010

44. Sakurai T and Kudo M: Signaling pathways governing tumor angiogenesis. Oncology 81 (Suppl 1): S24-S29, 2011.

45. Uchida C, Gee E, Ispanovic E and Haas TL: JNK as a positive regulator of angiogenic potential in endothelial cells. Cell Biol Int 32: 769-776, 2008

46. Aggarwal BB: Tumour necrosis factors receptor associated signalling molecules and their role in activation of apoptosis, JNK and NF-kappaB. Ann Rheum Dis 59 (Suppl 1): i6-i16, 2000.

47. Ham J, Eilers A, Whitfield J, Neame SJ and Shah B: c-Jun and the transcriptional control of neuronal apoptosis. Biochem Pharmacol 60: 1015-1021, 2000.

48. Xia Z, Dickens M, Raingeaud J, Davis RJ and Greenberg ME: Opposing effects of ERK and JNK-p38 MAP kinases on apoptosis. Science 270: 1326-1331, 1995.

49. Lenczowski JM, Dominguez L, Eder AM, King LB, Zacharchuk CM and Ashwell JD: Lack of a role for Jun kinase and AP-1 in Fas-induced apoptosis. Mol Cell Biol 17: 170-181, 1997.

50. Liu ZG, Hsu H, Goeddel DV and Karin M: Dissection of TNF receptor 1 effector functions: JNK activation is not linked to apoptosis while NF-kappaB activation prevents cell death. Cell 87: 565-576, 1996.

51. Tang F, Tang G, Xiang J, Dai Q, Rosner MR and Lin A: The absence of NF-kappaB-mediated inhibition of c-Jun N-terminal kinase activation contributes to tumor necrosis factor alpha-induced apoptosis. Mol Cell Biol 22: 8571-8579, 2002.

52. Papa S, Zazzeroni F, Pham CG, Bubici C and Franzoso G: Linking JNK signaling to NF-kappaB: A key to survival. J Cell Sci 117: 5197-5208, 2004.

53. De Smaele E, Zazzeroni F, Papa S, Nguyen DU, Jin R, Jones J, Cong R and Franzoso G: Induction of gadd45beta by NF-kappaB downregulates pro-apoptotic JNK signalling. Nature 414: 308-313, 2001.

54. Reuther-Madrid JY, Kashatus D, Chen S, Li X, Westwick J, Davis RJ, Earp HS, Wang CY and Baldwin Jr AS Jr: The p65/ RelA subunit of NF-kappaB suppresses the sustained, antiapoptotic activity of Jun kinase induced by tumor necrosis factor. Mol Cell Biol 22: 8175-8183, 2002. 